\title{
Performance Evaluation of Mobile Ad Hoc Networks with Reactive and Proactive Routing Protocols and Mobility Models
}

\author{
Sunil Kumar Kaushik \\ CSE Department, \\ HCTM TECHNICAL CAMPUS \\ KAITHAL -136027 (INDIA) \\ Kavita Chahal
ECE Department, HCTM TECHNICAL CAMPUS
KAITHAL -136027 (INDIA)

\author{
Sukhbir Singh \\ CSE Department, \\ HCTM TECHNICAL CAMPUS \\ KAITHAL -136027 (INDIA) \\ Sandeep Dhariwal \\ ECE Department, HCTM TECHNICAL CAMPUS \\ KAITHAL -136027 (INDIA)
}

\begin{abstract}
Mobile Ad hoc Network is a collection of wireless mobile nodes dynamically forming a temporary network without the aid of any established infrastructure or centralized administration. Routing protocols in mobile ad hoc network helps node to send and receive packets. In this paper we are doing study of AODV, DSR (Reactive), and OLSR, DSDV, TORA (Proactive) protocols based on various mobility models [3] such as RPGM, CMM and RWP . In this paper we evaluate performance of five types of routing protocols (AODV, DSR, OLSR, DSDV and TORA) based on packet delivery ratio, average end to end delay, routing overhead and throughput. In this paper we will analyze and compare the performance of reactive and proactive routing protocols under different mobility models using NS-2 simulator in the area of $700 \times 700 \mathrm{~m}^{2}$.
\end{abstract}

\section{Keywords}

MANET, AODV, DSR, OLSR, DSDV, TORA, RPGM, CMM and RWP

\section{INTRODUCTION}

A mobile ad hoc network [1, 2, 18] is a self-configuring infrastructure less network consisting of mobile nodes (Laptop, Personal Digital Assistants (PDAs) and wireless phones) with routing capabilities where each node operate both as host as well as router to forward the packets to each other, with the characteristics of self-organization and self configuration which enable it to form a new network quickly. In MANETs nodes are free to move randomly and join or leave the network when at their will. For this multiple hopes are needed to exchange data between nodes in the network. MANETs provide an emerging technology for civilian and military applications. Since the medium of the communication is wireless, only limited bandwidth is available. Another important constraint is energy due to the mobility of the nodes in nature. One of the important research areas in MANET is establishing and maintaining the ad hoc network through the use of routing protocols. Though there are so many routing protocols available, this paper considers AODV, DSR, OLSR, DSDV and TORA for performance comparisons with varying mobility models $[3,19,20]$ such as RPGM, CMM and RWP. These protocols are analyzed based on the important metrics such as throughput, packet delivery ratio, routing overhead and average end-to-end delay and is presented with the simulation results obtained by NS- 2 simulator. In particular, Section 2 presents the related works with a focus on the evaluation of the routing protocols. Section 3 briefly discusses the MANET routing protocols classification and the functionality of the five routing protocols AODV, DSR, OLSR, DSDV and TORA and section 4 briefly discusses about mobility models[3,19] such as RPGM, CMM and RWP . The simulation results and performance comparison of the overall performance of the Five routing protocols AODV, DSR, OLSR, DSDV and TORA with varying mobility models such as RPGM, CMM and RWP based on the throughput, packet delivery ratio, routing overhead and average end-to-end delay metrics are discussed in Section 5. Finally, Section 6 concludes with the comparisons and future work in same area.

\section{RELATED WORK}

Previous work in performance evaluation of routing protocols is reported in references [4-10]. In [4] and [5] DSR and AODV routing protocols are compared in different scenarios in terms of mobility and offered data load. STAR and DSVD, which are proactive routing protocols, are compared in [6] and [7] respectively, with DSR and AODV, which are reactive routing protocols. The authors of [8] and [9] compare their implementations of DSDV, TORA, DSR and AODV. In [10] reactive routing protocols AODV, PAODV, CBRP, DSR are compared with proactive protocol DSDV and the authors conclude that the four reactive protocols perform better than DSDV.

In [11] authors provide a simulation based performance evaluation and compare various reactive, proactive and hybrid protocols based on Random waypoint mobility models and compare the performance of three routing protocols (AODV,OLSR, ZRP) with the performance parameters such as packet delivery ratio, average end to end delay with using Qualnet 4.5. In [12] the authors compared the DSDV AODV DSR with existing mobility models used in the simulation of MANETs such as Random waypoint, Manhanttan Grid, GaussMarkov, Reference point Group and Heterogeneous Mobility Models.

In[13]the authors study the impact of mobility models in the performance of multicast routing protocols in MANET the author took Random waypoint models reference point models Manhattan Grid with three protocols ODMRP ,AODV and ADDV using NS-2 simulator and carry out their strength weakness and applicability of protocols with mobility models. In[14] the author compared the performance of three protocols DSDV AODV and DSR and find out that AODV DSR perform 
better in high mobility models than DSDV the performance matrix taken by the author are network load, network size with random waypoint mobility models .In [15] the author compares the random, group mobility, freeway mobility models and Manhanttan Grid mobility models using DSDV AODV and DSR Protocols. In [16] the author compare AODV DSDV and DSR using NS-2 simulator in Low load and low mobility scenario with various routing protocols and conclude that DSR outperform in high mobility and high load.

In [17] the author evaluate the performance of various MANET protocols such as DSDV, AODV, DYMO, OLSR, DSR with various mobility model such as RWP, RPGM,CMM with various performance parameters such as throughput, packet delivery ratio and minimizing delay routing load and energy congestion using NS-2 simulator with the varying area.

In this paper we will evaluate the performance of five types of routing protocols (AODV, DSR, OLSR, DSDV and TORA) based on packet delivery ratio, average end to end delay, routing overhead and throughput with different mobility models using NS-2 simulator in the area of $700 \times 700 \mathrm{~m} 2$.

\section{MANET ROUTING PROTCOLS}

There are two types of Routing Protocols in Mobile Ad Hoc Networks: Reactive Routing Protocols and Proactive Routing Protocols.

\subsection{Reactive Routing Protocols}

Reactive protocols also known as On-demand routing protocols which takes the passive approach or lazy to routing which is different with proactive routing protocols. Router are identified and maintained for nodes that require sending data to destination this is done by routing discovery mechanism to find the path to the destination $[1,2,18]$. This type of protocols find route by flooding the network with route request packets [1]. The reactive protocols discovered when needed. In this source nodes initiate route discover broadcasting route request into the network [2]. The discovered route maintained in the routing table however valid and kept and the old one are deleted after active route timeout. A serious issue for MANET occurs when the links are failure due to high node mobility. This is cause for increase in the traffic with link break make effects of intermediate nodes [2]. AODV, DSR, ROAM, LMR, TORA, ABR, SSA, RDMAR, LAR, ARA, FORP and CBRP are the example of routing protocols.

- DSR-Dynamic source routing protocol [1,2,18] comes under the category of Reactive protocol for Ad-hoc wireless network. It is not table-driven but instead of that it has the characteristics like AODV. This protocol is truly based on source routing whereby all the routing information is maintained (continually updated) at mobile nodes. It has only two major phases, which are Route Discovery and Route Maintenance. Route Reply would only be generated if the message has reached the intended destination node (route record which is initially contained in Route Request would be inserted into the Route Reply).This type of routing is different from table-driven and link-state routing in the form of decision making.

- AODV-Ad-hoc On Demand Distance Vector is an on demand routing algorithm that builds route only when needed and also known as Source Initiated Routing Protocol $[1,2,18]$. AODV works on the principle of Route Request (RREQ), Route Reply (RREP) and Route Error
(RERR). Each node has its own routing table which contains the information about the route from source to destination. In AODV for route maintains nodes periodical send Hello Message to its neighbor .If in any case the node fails to receive three consecutive Hello Message from the neighbor it conclude that the link to that specified node is down and get a route error message from the lower stream nodes and then the other node have to discover new route.

- TORA---The Temporally-Ordered Routing Algorithm is a highly adaptive scalable and efficient distributed routing algorithm which works on the principle of link reversal $[1,2,18]$.In TORA the source initiate the demand for the route to send the packet to the destination and find many routes from source to destination then choose one from them. This protocols based on three function (1)Route Creation for creating the route source to destination.(2) Route maintenance maintain the session during the packet transfer(3)Route Eraser use for ending the session of data sending and ensure that the occupied route is free. TORA maintains various routes to avoid the effect of topological change. In TORA we need not to maintain the update but the utilization of the bandwidth is minimized. TORA can be maintained with the help of DAG (Dynamic acyclic graph)[1].

Table 1: Comparisons of AODV, DSR and TORA Routing Protocols

\begin{tabular}{|c|c|c|}
\hline PROTOCOLS & ADVANTAGES & DISADVANTAGE \\
\hline AODV & $\begin{array}{c}\text { Adaptable to high } \\
\text { Dynamic topology }\end{array}$ & $\begin{array}{c}\text { Scalability Problem, } \\
\text { Large Delay, Hello } \\
\text { Message }\end{array}$ \\
\hline DSR & $\begin{array}{c}\text { Multiple Routes. } \\
\text { Promiscuous Over } \\
\text { heading }\end{array}$ & $\begin{array}{c}\text { Scalability Problem due } \\
\text { to source routing \& } \\
\text { flooding, Large delay }\end{array}$ \\
\hline TORA & Multiple Routes & $\begin{array}{c}\text { Temporary Routing } \\
\text { Routes }\end{array}$ \\
\hline
\end{tabular}

Table 2: Basic Characteristics and Comparisons of AODV, DSR and TORA Routing Protocols Routing Protocols

\begin{tabular}{|c|c|c|c|c|c|}
\hline PROTOCOL & RS & $\begin{array}{c}\text { MULTIPLE } \\
\text { ROUTES }\end{array}$ & BEACONS & $\begin{array}{c}\text { ROUTE } \\
\text { METRIC } \\
\text { METHOD }\end{array}$ & $\begin{array}{c}\text { ROUTE } \\
\text { MAINTAINED IN }\end{array}$ \\
\hline AODV & F & NO & $\begin{array}{c}\text { Yes, } \\
\text { Hello } \\
\text { Message }\end{array}$ & $\begin{array}{c}\text { Freshest } \\
\text { \& SP }\end{array}$ & RT \\
\hline DSR & F & YES & NO & $\begin{array}{c}\text { SP Or } \\
\text { Next } \\
\text { Available } \\
\text { In RC }\end{array}$ & RC \\
\hline TORA & F & YES & NO & $\begin{array}{c}\text { SP Or } \\
\text { Next } \\
\text { Available }\end{array}$ & RT \\
\hline
\end{tabular}

RS-Routing Structure, F-Flat, RT-Routing Table, RC-Routing Cache, SP-Shortest Path,

\subsection{Proactive Routing Protocols}

Routing protocols are table-Driven protocols when each nodes maintain a route to old destination in its routing table [1]. Proactive protocols also determine the route for various nodes in the network in advance, so that the route is already present whenever needed. Route overhead are larger in such schemes in compare to reactive protocols $[1,2,18]$. DSDV, WRP, GSR, FSR, STAR, DREAM, MMWN, HSR, OLSR and TBRPF are 
some of example of proactive protocols. In case of route failure Route-error packet is sent by the source to destination nodes. All the route information is usually kept in numbers of different tables $[2,18]$. Whenever the change occur these table updated according to change.

- DSDV-Destination sequence distance vector protocol $[1,2,18]$ is a table-driven routing scheme for ad hoc mobile networks based on the Bellman-Ford algorithm and developed by C. Perkins in 1994. This algorithm is used for calculating or finding the shortest path between the multiple paths and as the same suggest the source select the path which has minimum, distance from source to destination. The main contribution of the algorithm was to solve the routing loop problem. Each entry in the routing table contains a sequence number, the sequence numbers are generally even if a link is present; else, an odd number is used. The number is generated by the destination, and the emitter needs to send out the next update with this number. The update in the table can be done by two method one is full dump where node transmit their Routing table entry and other is incremental method where the node only forward newly updated entry[2].

- OLSR--The Optimized Link State Routing Protocol is a Proactive link state protocol .OLSR employs three mechanism for routing (1)Hello message for neighbor sensing message (II)Control packet using multi-point rely(MPR).(III)Path selection using shortest path first algorithm.[2]. Each nodes using its two-hops by selecting MPR's such that all its two-hop neighbors are accessible .Basically the hello and topology control (TC) messages to discover and then broadcast link state information throughout the mobile ad-hoc network. Individual nodes use this topology information to compute next hop destinations for all nodes in the network using shortest hop forwarding paths [18].

Table 3: Comparisons of DSDV and OLSR Routing Protocols

\begin{tabular}{|c|c|c|}
\hline PROTOCOLS & ADVANTAGES & DISADVANTAGE \\
\hline DSDV & Loop Free & High Overhead \\
\hline OLSR & $\begin{array}{c}\text { Reduce Control } \\
\text { Overhead \& } \\
\text { Contention }\end{array}$ & $\begin{array}{c}2 \text { Hops Neighbors } \\
\text { Knowledge } \\
\text { Required }\end{array}$ \\
\hline
\end{tabular}

Table 4: Basic Characteristics and Comparisons of DSDV and DSR Routing Protocols Routing Protocols.

\begin{tabular}{|c|c|c|c|c|c|}
\hline PROTOCOL & $\begin{array}{c}\mathbf{R} \\
\mathbf{S}\end{array}$ & $\begin{array}{c}\text { NO.OF } \\
\text { TABLES }\end{array}$ & $\begin{array}{c}\text { FREQUENCY } \\
\text { OF UPDATE }\end{array}$ & HM & $\begin{array}{c}\text { CRITICAL } \\
\text { NODE }\end{array}$ \\
\hline DSDV & $\mathrm{F}$ & 2 & $\begin{array}{c}\text { Periodic \& as } \\
\text { Required }\end{array}$ & YES & NO \\
\hline OLSR & $\mathrm{F}$ & $\begin{array}{c}\text { 3(Routing } \\
\text { Neighbors } \\
\& \\
\text { Topological } \\
\text { table) }\end{array}$ & Periodic & YES & NO \\
\hline
\end{tabular}

RS-Routing Structure, F-Flat, HM-Hello Message,

\section{MOBILITY MODELS}

A mobility model which represents movement behavior of considered application scenarios should incorporate and is an important feature that may change characteristics of mobile nodes. It describes how speed, acceleration and direction of the node changes over time. In order to check the performance of various mobility model the result of a protocol for an ad hoc network, the protocol should be tested under realistic conditions such as the transmission of the packets in sensible transmission range, limited buffer space for storage of messages with various data traffic models, and realistic movement of mobile nodes. In the MANET there are various mobility models $[3,19,20]$ such as Random Walk Mobility Model, Random Waypoint Mobility Model, Reference Point Group mobility Model, Boundless Simulation Area Mobility Model, Gauss-Markov Mobility Model, Probe Walk Mobility Model, Column Mobility Model and City Section Mobility Model. In this paper we are comparing the performance of various reactive and proactive protocols with the RPGM, RWP and CMM mobility models with aim to packet delivery ratio, throughput and end to end delay and routing overhead.

\subsection{RPGM (Reference Point Group mobility Model)}

RPGM is a mobility model with spatial dependency to simulate group behavior in $[19,20]$, where each node belongs to a group where every node follows a logical center (group leader) that determines the group's motion behavior.

RPGM is a group mobility model where the nodes form a group and then moves in a coordinate manner. It also represents the random motion of a group of mobile nodes as well as the random motion of each individual mobile node within the group. The nodes in a group are usually randomly distributed around the reference point. Group movements are based upon the path traveled by a logical center for the group. There may be a case where Individual mobile nodes randomly move about their own pre-defined reference points and there may be change in the performance of the network.

The different nodes use their own mobility model and are then added to the reference point which drives them in the direction of the group. At each instant, every node has a speed and direction that is derived by randomly deviating from that of the group leader. This general description of group mobility can be used to create a variety of models for different kinds of mobility applications.

\subsection{CMM (Column Mobility Model)}

CMM $[3,19,20]$ is a mobility model with spatial dependency also and this model is derived from RPGM. It is a set of mobile nodes that move around a given line or column, which is moving in a forward direction or row. A minor modification of the Column Mobility Model allows the individual mobile nodes to follow one another node at the time of movement. For the implementation of this model, we have an initial reference grid which forms the column for mobile nodes. Each mobile node is then placed in relation to its reference point in reference grid; the mobile node is then allowed to move randomly around its reference point via an entity mobility model. The new reference point for a new mobile node is calculated by the following : New_reference_point $=$ Old_reference_point + Advance_ vector.

\subsection{RWP (Random Waypoint Model)}

The Random Waypoint Model was first proposed by Johnson and Maltz $[3,19,20]$. Soon, it became a 'benchmark' mobility model to evaluate the MANET routing protocols, because of its simplicity and wide availability.

The Random waypoint model is a random model for the movement of mobile users, and how their location, velocity and acceleration change over time. RWP mobility model is the most common mobility model used in research community [3].

In this model initially, all the mobile nodes are distributed over the simulation area randomly. Node selects its destination randomly among the others in simulation area. After choosing the random destination it chooses the velocity from a uniform 
distribution. After reaching the destination node, it stops for small time which is called the "pause time". The MN randomly selects the next destination in the simulation area and chooses a speed uniformly distributed between the minimum speed and maximum speed and travels with a speed whose value is uniformly chosen in the interval is some parameter that can be set to reflect the degree of mobility. Then, the MN continues its journey toward the newly selected destination at the chosen speed. As soon as the MN arrives at the destination, it stays again for the indicated pause time before repeating the process $[3,19,20]$. After the pause time duration it again chooses the destination randomly and moves toward that destination.

\section{SIMULATION ANALYSIS AND RESULT}

In this paper, we use NS simulator for simulating different routing protocols. NS simulator uses a visual tool called NAM. NAM is a Tcl/TK based animation tool for viewing network simulation traces and real world packet trace data. we are using the topology of $700 \times 700 \mathrm{~m}^{2}$ with $25,50,75,100$ nodes we are increasing only total number of nodes with keeping the total area constant i.e $700 \times 700 \mathrm{~m}^{2}$, speed $20 \pm 3 \mathrm{~m} / \mathrm{s}$, pause time $15 \pm 3 \mathrm{~s}$, packet size $512 \mathrm{~B}$, simulation time is 300 s and Traffic Node 10, $20,40,60$ respectively with $25,50,75,100$ nodes in the simulation. We discuss the effect of mobility on the Packet delivery Ratio , Average End-to-End delay, Normalized Routing Load and Throughput of the mobile ad-hoc network.

\subsection{Packet Delivery Ratio:}

Packet delivery Ratio (PDR): this is the ratio of total number of packets successfully received by the destination nodes to the number of packets sent by the source nodes throughout the simulation. It also describes the loss rate that of the packets, which in turn affects the maximum throughput that the network can support.

$\mathrm{PDR}=($ Packets Received $/$ Packets Sent $) * 100$

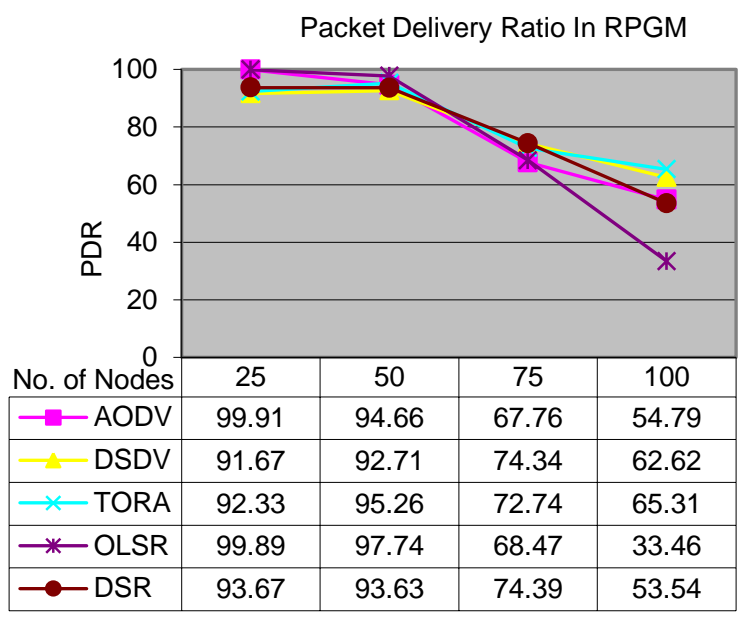

Fig 1: Packet Delivery Ratio (PDR) for RPGM

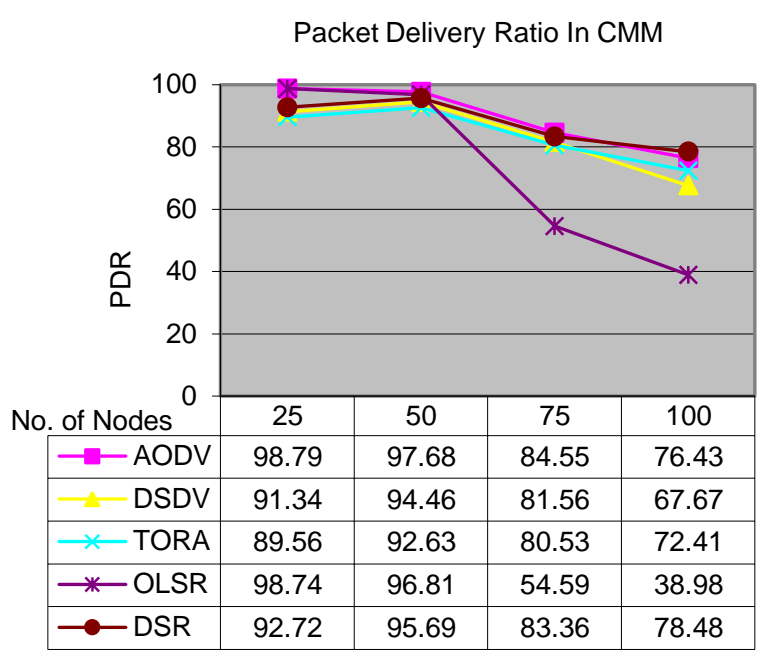

Fig 2 : Packet Delivery Ratio (PDR) for CMM

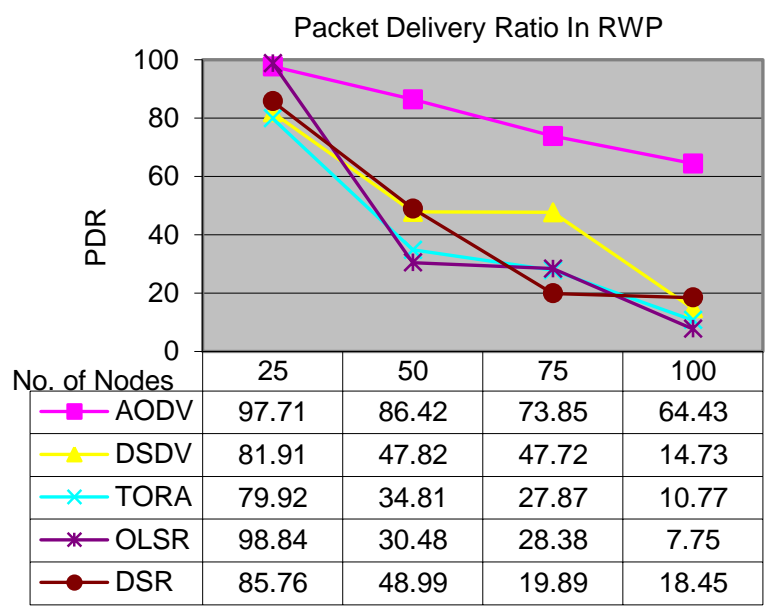

Fig 3: Packet Delivery Ratio (PDR) for RWP

\subsection{Average End To End Delay:}

Average End-to-End delay (AED): this is defined as the average delay in transmission of a packet between two nodes and a higher value of end-to-end delay means that the network is congested and hence the routing protocol does not perform well Average end-to-end delay (AED) is calculated as follows: 


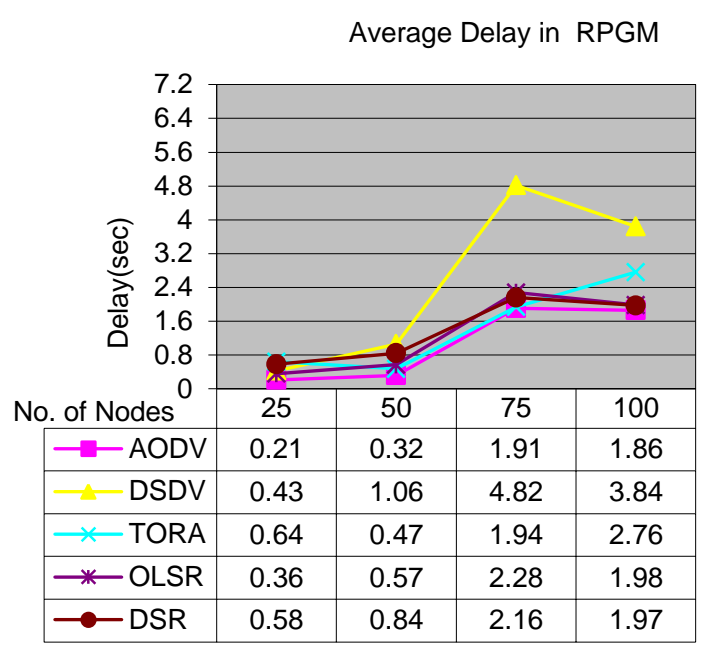

Fig 4: Average End-to-End delay (AED) for RPGM

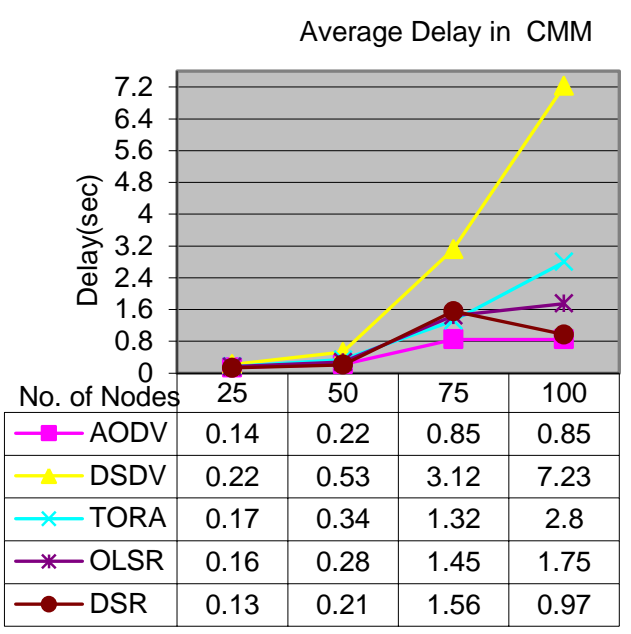

Fig 5: Average End-to-End delay (AED) for CMM

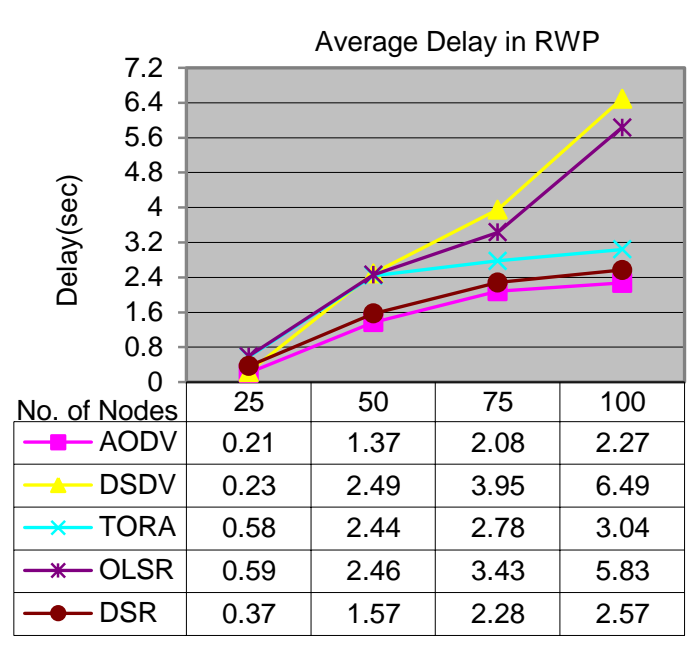

Fig 6: Average End-to-End delay (AED) for RWP

\subsection{Normalized Routing Load:}

This is calculated as the ratio between the numbers of routing Packets transmitted to the number of packets actually received (thus accounting for any dropped packets). The higher theNRL, the higher the overhead of routing packets and consequently the lower the efficiency of the protocol. It is defined as Number of routing packets "transmitted" per data packet "delivered" at destination. Each hop-wise transmission of a routing is counted as one transmission. It is the sum of all control packet sent by all node in network to discover and maintain route.

NRL is calculated by

NRL = Routing Packet/Received Packets.

Performance Evaluations (from graph)

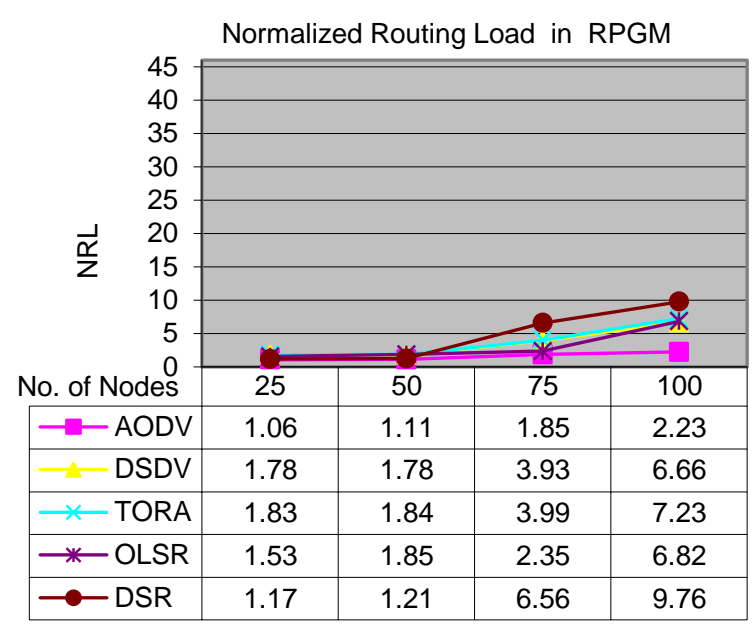

Fig 7: Normalized Routing Load (NRL) for RPGM 


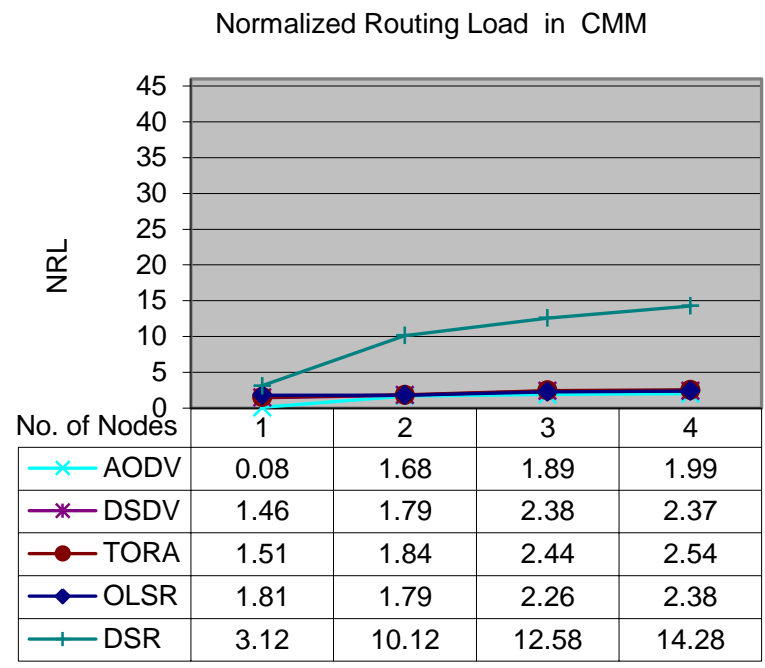

Fig 8: Normalized Routing Load (NRL) for CMM

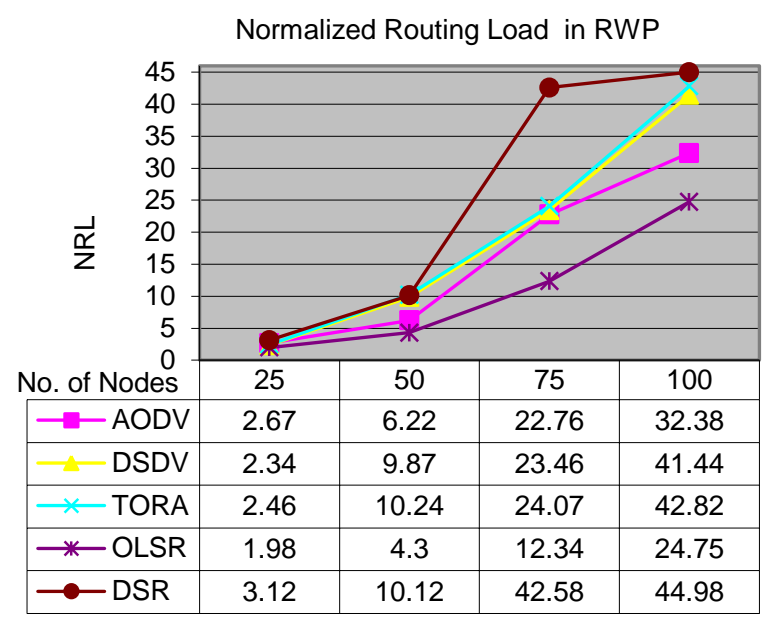

Fig 9: Normalized Routing Load (NRL) for RWP

\subsection{Throughput:}

The average rate at which the total number of data packet is delivered successfully from one node to another over a communication network is known as throughput. The result is found as per $\mathrm{KB} / \mathrm{Sec}$. It is calculated by

Throughput $=($ number of delivered packet $*$ packet size $) /$ total duration of simulation

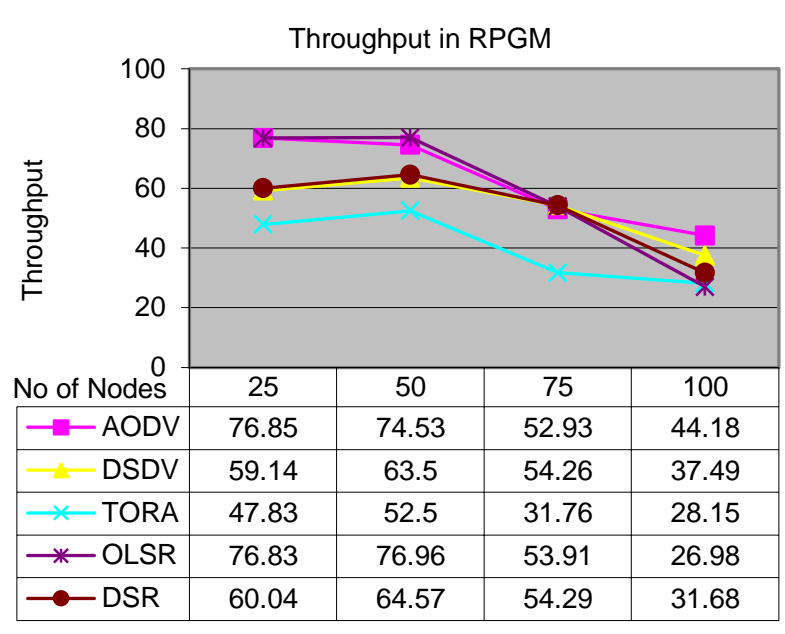

Fig 10: Throughput for RPGM

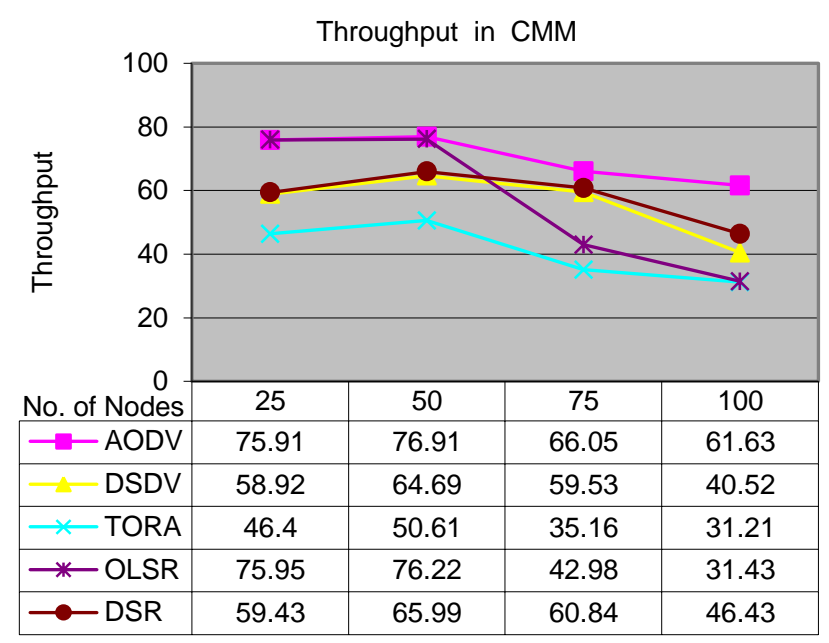

Fig 11: Throughput for CMM 


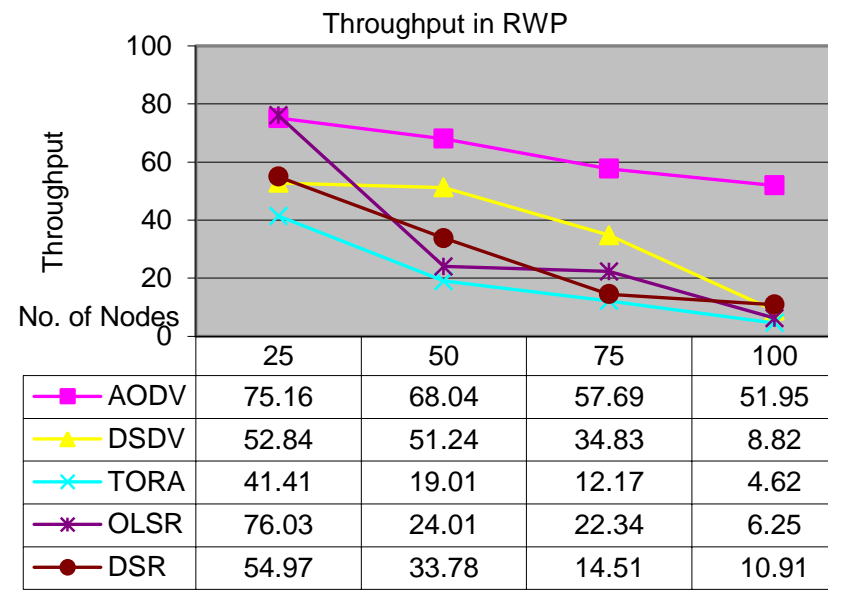

Fig 12: Throughput for RWP

\section{CONCLUSION}

In this paper, We have analyzed the behavior of Five MANETs routing protocols i.e. AODV, DSDV, DSR, OLSR, TORA under the three mobility models (RPGM,CMM,RWP) And then compare the performance of protocols using NS-2 simulator in the area of $700 \times 700 \mathrm{~m} 2$ which clearly indicate the significant impact on node mobility pattern has on routing performance, these routing protocols were compared in the manner of Packet delivery ratio (PDR), Average End to End delay (delay), Normalized routing load(NRL) and Throughput when subjected to change in numbers of nodes. Our simulation results show that Reactive protocols is much better than proactive in the manners of packet delivery (PDR), A End-to-End delay(Delay), Normalized routing load(NRD) and throughput . In this paper we look increase the number of nodes has impact on all protocols under these mobility models i.e the degradation varies for different protocols and mobility models. In this research our results is made into how well AODV, DSDV, DSR, OLSR and TORA work to different network conditions in MANET. The delay of OLSR is less and in the DSR is worst. Throughput is high in case of AODV. In DSR delay is greater than the AODV and OLSR. In the terms of packet dropper the DSDV perform better and consistently well with increase number of nodes while the AODV is worst. On the other hand DSR perform better when the numbers of nodes are less but it will fails when the numbers of nodes increase but DSR showed high end to end delay due to formation of temporary loops within the network . TORA is very poor and not reliable for the MANETs. In future, we can evaluate the performance of these five routing protocols under three mobility models by varying it to the speed, pause time..

\section{REFERENCES}

[1] E.M. Royer, C.-K. Toh, A review of current routing protocols for ad hoc mobile wireless networks, IEEE Personal Communications 6 (2) (1999) 46-55.

[2] M. Abolhasan, T. Wysocki, "A review of routing protocols for mobile ad hoc networks", Ad Hoc Networks, Vol. 2, Issue 1, pp 1-22, 1 January 2004.
[3] Santosh Kumar ,S C Sharma and Bhupendra Suman ," Classification and Evaluation of Mobility Metrics for Mobility Model Movement Patterns in Mobile Ad-Hoc Networks ",International journal on applications of graph theory in wireless ad hoc networks and sensor networks (GRAPH-HOC) Vol.3, No.3, September 2011.

[4] R. Misra, C. R. Mandal, "Performance comparison of AODV/DSR on-demand routing protocols for ad hoc networks in constrained situation", IEEE Int. Conf. on Personal Wireless Communications, pp. 86- 89, Jan. 2005.

[5] G. Jayakumar, G. Ganapathy, "Performance Comparison of Mobile Ad-hoc Network Routing Protocol", Int. J. of Comp. Science and Network Security, Vol.7, No.11, Nov. 2007.

[6] H. Jiang and J. J. Garcia-Luna-Aceves. Performance comparison of three routing protocols for ad hoc networks In Proceedings of IEEE ICCCN 2001, pages 547-554, 2001.

[7] P. Johansson, T. Larsson, N. Hedman, B. Mielczarek, and M. Degermark, "Scenario-Based Performance Analysis of Routing Protocols for Mobile Ad Hoc Networks", 5th ACM/IEEE Int. Conf. on Mobile Computing and networking, pp. 195-206. 1999.

[8] J. Broch, D. A. Maltz, D. B. Johnson, Y. Hu, J. Jetcheva, "A Performance Comparison of Multi-Hop Wireless Ad Hoc Network Routing Protocols", Proc. of the 4th ACM/IEEE Int. conf. on Mobile computing and networking, pp. 85-97. 1998.

[9] Li Layuan, Li Chunlin, Yaun Peiyan, "Performance evaluation and simulations of routing protocols in ad hoc networks", Computer Communications, Vol. 30, pp 18901898. 2007.

[10] Azzedine Boukerche, "Performance Evaluation of Routing Protocols for Ad Hoc Wireless Networks", Journal of Mobile Networks and Application, Vol. 9, No 4. pp.333342,2004

[11] Parma Nand , S.C.Sharma, "Comparative Study and Performance Analysis of FSR,ZRP and AODV Routing Protocols for MANET", IJCA Proceedings on International Conference and workshop on Emerging Trends in Technology (ICWET) (2):14-19, 2011.

[12] Ejiro.E.Igbesoko, Thaddeus Onyinye Eze, Mona Ghassemian"Performance Analysis of MANET Routing Protocols over Different Mobility Models", In proceedings of London Communications Symposium (LCS), University College London, Sept. 2010 http://www.ee.ucl.ac.uk/lcs/previous/.../lens2010_submissio n_18.pdf

[13] R. Manoharan and E. Ilavarasan,"Impact of Mobility On The Performance of Multicast Routing Protocols In MANET", International Journal Of Wireless and Mobile Networks (IJWMN). Vol 2, No.2, May 2010.

[14] Santosh Kumar , S C sharma, Bhupendra Suman,"Simulation Based Performance Analysis of routing \{rptpcp;s Isomg Ramdp, Waypoint Mobility Model in Mobile Ad Hoc Network", Global Journals inc. (USA), Vol. 11,Issue 1.Version 1.0 Feb.2011, ISSN:0975-4172

[15] Vivek Thapar, Bindiya Jain, Varsha Sahni, "Performance Analysis Of Ad hoc Routing Protocols Using Random Waypoint Mobility Model In Wireless Sensor", 
International Journal On computer Science and Engineering (IJCSE),Vol. 3No.8 August 2011 ISSN: 0975-3397.

[16] F. Bai, N. Sadagopan, and A. Helmy, Important: a framework to systematically analyze the impact of mobility on performance of routing protocols for ad hoc networks, in Proceedings of IEEE Information Communications Conference (INFOCOM 2003), San Francisco, Apr. 2003.

[17] Fahim Maan Nauman Mazhar "MANET Routing Protocols vs. Mobility Models: A Performance Evaluation", in Proceedings of IEEE Conference ICUFN 2011, pp. 179184.

[18] Tanu Preet Singh, Dr. R K Singh and Jayant Vats. Article: Routing Protocols in Ad Hoc Networks: A Review. International Journal of Computer Applications 25(4):3035, July 2011.
[19] F. Bai and A. Helmy, "Wireless ad hoc and sensor networks", Chapter 1: "A survey of mobility models", 2004, http://nile.usc.edu/ helmy/important/ModifiedChapter1-5-30-04.pdf.

[20] T. Camp, J. Boleng, and V. Davies, A Survey of Mobility Models for Ad Hoc Network Research, in Wireless Communication and Mobile Computing (WCMC): Special issue on Mobile Ad Hoc Networking: Research, Trends and Applications, vol. 2, no. 5, pp. 483-502, 2002. 